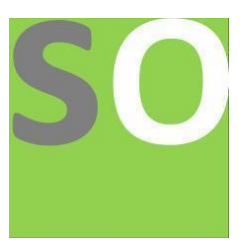

Article title: Effect of Cold Storage on Livability and Progressive Motility of Cauda Epididymal Spermatozoa of Red Sokoto Buck Recovered Post Mortem

Authors: Faith Chinonye Eke[1], Terzungwe Ahemen[2]

Affiliations: Department of Animal Breeding and Physiology, University of Agriculture Makurdi, Benue State Nigeria[1]

Orcid ids: 0000-0001-9426-4151[1]

Contact e-mail: faithchinonye53@gmail.com

License information: This work has been published open access under Creative Commons Attribution License http://creativecommons.org/licenses/by/4.0/, which permits unrestricted use, distribution, and reproduction in any medium, provided the original work is properly cited. Conditions, terms of use and publishing policy can be found at https://www.scienceopen.com/.

Preprint statement: This article is a preprint and has not been peer-reviewed, under consideration and submitted to ScienceOpen Preprints for open peer review.

Funder: Self-funding

DOI: 10.14293/S2199-1006.1.SOR-.PPODVYP.v1

Preprint first posted online: 21 November 2021

Keywords: Cold Storage, Livability, Progressive Motility, Cauda Epididymal Spermatozoa, Red Sokoto Buck, Post Mortem 


\title{
Effect of cold storage on livability and progressive motility of cauda epididymal spermatozoa of red sokoto buck recovered most mortem
}

\begin{abstract}
Postmortem spermatozoa recovery is an important tool for harvesting germplasm. The study aimed to determine the effect of cold storage time at $4{ }^{\circ} \mathrm{C}$ for 48 and 72 hours on the quality of sperm of Red Sokoto buck caudal epididymaly spermatozoa in terms of motility and livability recovered postmortem.

Fifteen testicles with attached epididymis were collected and processed at 0 , 48, and 72 hours of storage. The samples were divided into 3 groups according to the time processing after collection; 0 hour, 48 hours and 72 hours, with a total of 5 samples per group. Each storage group motility and livability was evaluated, mean and the standard error of their mean was recorded. Mean percent sperm motility declined significantly ( $p<$ 0.05 ) as postmortem storage time increased ( motility: $79.00+/-2.92 \%, 40.00+1-4.18$, $37.00+/-3.39)$.There was no significant $(p>0.05)$ decrease in livability from the 0 hour storage to the 48 hour and 72 hours storage ( $75.60+/-4.40,73.60+/-3.84,68.20+/$ 2.51).
\end{abstract}

The current study has shown that viable spermatozoa can be recovered after 48 hours of storage at $4^{\circ} \mathrm{C}$ of the cauda epididymides Red Sokoto buck.

\section{Introduction}

The ability to preserve genetic material is an important tool in conserving genetic variation in endangered populations and species. Biobanks play an integral part in worldwide conservation efforts, in both domesticated and wild species, to counteract the loss of genetic diversity. Furthermore, material in animal biobanks is useful for various types of research, such as cryobiology, reduction of inbreeding, genomic selection studies, assessment of genetic distances and disease genetics (Blackburn, 2012; Groeneveld et al., 2016).

When working with domesticated animals, zoo animals and wildlife populations of threatened animals, the number of breeding males is often limited to a few superior animals. Many populations show harem structures with highly skewed mating ratios, and managing a large number of mature breeding males can be problematic from an economic or practical point of view (Sánchez et al., 2003; Sørensen et al., 2005; Maksudov et al., 2008). For breeding and preservation of genetic material, spermatozoa are normally collected through ejaculation, but this is not possible in all species or in every situation, such as in instances of unexpected death or after castration. Furthermore, animals in captivity face various issues, such as space limitations, skewed sex ratios and surplus animals, which leads to euthanization of a number of animals every year. Taken together, 
several animals die without being used for breeding purposes and thus represent an unexploited source of genetic material (Maksudov et al., 2008). Therefore, suitable protocols for recovery of spermatozoa after the animal's death will enable us to exploit and preserve genetic material by cryopreservation of spermatozoa or in vitro production of embryos.

Recovery of the epididymal spermatozoa helps to ensure that the genetic materials of a highly priced or valuable animal are not lost.Retrieval and short term storage of the epididymal sperm under refrigeration temperature for transport to sperm banks for long term cryopreservation or to areas where they could be used immediately for artificial insemination provides an avenue to preserve the genetic materials of such an animal. The conditions (temperature, time, and environment) under which the epididymides are transported to the laboratory or sperm bank could affect the quality of the spermatozoa. To the best of our knowledge, little work has been done on the effects of cold storage on the quality of cauda epididymal spermatozoa of Nigerian goats.

\subsection{Objectives of the study}

The study aims at determining the effect of cold storage on livability and progressive motility of

cauda epididymal spermatozoa of red sokoto buck recovered most mortem. 


\subsection{LITERATURE REVIEW}

\subsection{GOAT POPULATION AND DISTRIBUTION}

Goats are cloven-footed animals which are called small ruminants, and belong to the genus Capra. Goats were domesticated over 8000 years ago, in Africa (along river Nile), Asia (along Tigris and Euphrate rivers), and India Idus). The breeds of goats in Nigeria are thought to have originated from Western Asia passing through the Middle East to North Africa and finally to Nigeria. They are ruminants like cattle because they chew the cud or regurgitate and ruminate, and have four stomachs. The population of goat in Nigeria as at 2011 was estimated by the Nigeria Agricultural Sample survey to be around 72.5 million. There are more goats in the North than there are in the South. Goats are found more in the villages than in the urban areas.

\subsection{IMPORTANCE OF GOATS}

Goats play important roles in the socio-economic and cultural lives of the people in the following ways:

(1.)They provide meat and milk to humans. In most parts of Nigeria, small ruminants, especially goats are slaughtered for consumption almost routinely.It is important to note however that the meat from goat is only used to supplement or augment the one from cattle which are the major producers of meat for Nigerians. In terms of milk supplies from small ruminants, the breeds of goats we have in Nigeria produce more milk than the breeds of sheep. Again, the quantity of milk produced is smaller in volume compared to that of cattle, and is used to augment supplies from cattle in some parts of northern Nigerian to increase the volume available for sale. Hitherto, the apathy towards consumption of goat milk was high, but continued enlightenment on the unique good qualities of goat milk for human health is making an increasing number of people to accept goat milk.

(2.)They produce wool, hair and skin and manure. Goats produce fibre which is used in fabric industries. Skins are by-products after slaughter, and are used in making shoes and other leather products. The skin from the Red Sokoto goats popularly known “Moroco" leather is highly sought after in the leather trade in the international market. It earns Nigeria some foreign exchange. The Faecal droppings from goats are used as manure to enrich the soil of its nutrients content. The scarcity and high cost of inorganic fertilizer have made the demand for sheep and goat manure to increase. 
(3.) Goats serve as a form of investment. Some farmers prefer to store their wealth in the form of livestock. Goats can be converted into cash quickly by being sold when the need arises. Given the absence of diseases and mortality, investment in goats can protect against losses due to high inflation rates characteristic of unstable economies of many developing nations like Nigeria.

(4.)In some cultures or communities in Nigeria, sheep and goats are used to achieve/fulfil certain and burial ceremonies. They form part of dowry, and are offered to parents sometimes as a mark of respect.

\subsection{BREEDS OF GOATS IN NIGERIA}

\subsubsection{West African Dwarf Goat(WAD)}

West African Dwarf (WAD) goat is common to Southern Nigeria (Wilson ,1991).This breed is markedly stunted and has a typical height of 30 to $50 \mathrm{~cm}$. Adult males weigh 20 to 25 $\mathrm{kg}$ and females 18 to $22 \mathrm{~kg}$. Both sexes have horns, which curve outwards and backwards in males. Males also have beards, and sometimes manes. The neck is relatively long, the chest is broad and the back straight. The legs are short and the udder is small but usually well-shaped. Most types have short stiff hair, and the colour varies; dark brown with black points is probably the most common, but black, red, white, pied and multi-coloured goats also occur(Wilson, 1991). West African Dwarf goats are capable of breeding at twelve to eighteen months. Multiple births are very common with twins being normal and triplets frequent. The kidding interval averages about 220 days. Growth rate and milk yield of this breed is very low; it is kept for meat production. The breed is well adapted to humid environment and very resistant to trypanosomiasis (Ozung et al., 2011; Chiejina et al.,2015).

\subsubsection{Sahel Goat}

The Sahel or Desert goat is found along the northern border of Nigeria. This goat is believed by the local Hausa/Fulanis who are the original custodian of the breed to have originally come from the dry lands of Niger (Otoikhian,2012). They have thin appearance, narrow body, shallow chest, and sloping short croup. Long spindly legs. Udder as well as scrotum in males split into two halves. Both sexes horned, most (70\%) with wattles, pendent or semi-pendulous ears. Average females weight about 55-75 pounds, height in withers $65-75 \mathrm{~cm}$, heart girth $62-78 \mathrm{~cm}$, males about $85-125$ pounds, $65-85 \mathrm{~cm}$ in withers and $70-85 \mathrm{~cm}$. in heart girth. 


\subsubsection{Red Sokoto Goats}

The Red Sokoto, Kano Brown or Maradi goats are found in Nigeria and Niger (Ozung et al., 2011). Within the indigenous breeds of goats kept for meat production in Nigeria, Red Sokoto goat is the most numerous and most widely distributed throughout the various ecological zones,

particularly Guinea and Sudan savannah vegetation belt (Ibrahim et al., 2014). It measures between $55-60 \mathrm{~cm}$ height at withers with an average mature live weight of $25 \mathrm{~kg}$ (Otoikhian, 2012). Red Sokoto is a large, fast growing, early - maturing meat breed (Ebozoje, 1992). It is a small fine goat famous for its skin (Ozung et al., 2011). The skin of Red Sokoto is known for its superior quality and the premium it commands in the world market (Otoikhian, 2012). Red Sokoto was the source of „Morocco leather" known in Europe from the medieval period onwards (Blench, 1999). This breed is a good dairy animal which produces a daily milk yield of 0.5 to $1.5 \mathrm{~kg}$ and 100 days of lactation (Gall, 1996).

\subsection{MANAGEMENT SYSTEMS OF GOAT PRODUCTION}

\subsubsection{Extensive goat production systems}

Extensive systems are characterized by large areas to feed the animals, with a low animal density. It uses soils of poor agricultural ability, located in mountainous areas with large rainfall or in areas of low rainfall, sometimes with extreme temperatures. The goat production in this extensive system uses family labor, often as a second source of income for families. The goat milk is obtained for family consumption or for cheese to sale. However, the sale of the kid goat is the main reason for this production. In the Southern Mediterranean, this product is very appreciated and valued, mainly in the Easter and Christmas seasons. Usually, the number of animals produced is low and they are usually raised under climate adversities, where probably there are no shelters, no food supplementation and also often these animals have hygienic sanitary problems, which leads to poor economic results. It turns out that the use of natural pastures can be done in two ways, a mobile grazing system and a sedentary grazing system. The first is characterized by annual or seasonal movements of the animals with the shepherd to new places in search for feed, and while sedentary grazing, the animals are driven freely to pastures near the farm, usually keeping the animals at night in the stable.

In the mountains, they can practice transhumance, which consists of seasonal movement of animals regularly between two or more areas of seasonal pasture, through established paths (called “canadas” in Portugal and Spain), conducted by shepherds in the summer to the mountain to take advantage of the still fresh pastures and return to the valley in early 
autumn. This modality is currently disappearing due to sanitary issues and also because of the greater easiness to feed the animals through the purchase of commercial feeds. Although the extensive production is not very productive, it is of great importance regarding the maintenance of the rural landscape and with the aim of the biomass management that avoids the occurrence of forest fires, and where the goats are well adapted to take advantage of these feed resources.

\subsubsection{Intensive goat production systems}

Intensification is often associated with a decrease in grazing dependence and an increase in the use of concentrated feeds, mainly cereals, to supplement natural feeds. At the same time, improved and balanced feeding practices together with improved breeds in ruminant systems enabled more efficient feed ratio conversion to meat and milk production rather than to maintenance of the animals. The intensive system implies a high density or animal concentration per area unit, under reproductive and sanitary control, and the feeding process includes advanced technologies. Sometimes, some farms seasonally require higher feed and labor resources such as through the calving season and milk production, so the supplementing of animals with concentrated feed may be needed at this point, but the remaining year is mainly grazing. In order to meet the feed requirements of animals in an intensive system, pastures must have high dry matter yields per hectare, good growth throughout the year, in both regions with regular rainfall or holdings with irrigation systems, without extremes of heat or cold temperatures.

\subsection{REPRODUCTION IN BUCK}

The male goat is called a "buck" or "billy." If he is castrated, he is called a "wether." Male goats up to 12 months of age are sometimes referred to as "bucklings." Adult male goats can weigh anywhere between 100 to 350 pounds, depending on their breed, health and nutritional status. Although they can come into puberty and breed does as early at 4 months of age, waiting until a buck is a year of age to start using him for breeding is best. The number of does a buck can breed during the breeding season is often referred to as “Buck Power” (Noble, 2004).

At 1 year of age, the buck should service no more than 10 does at a time (in one month). When he is 2 years old, he should be able to service 25 does at a time. At the age of 3 and older, he can breed up to 40 does at one time, as long as his health and nutritional needs are met. The number of does a buck can service at one time also depends on individual sex drive of the buck, the terrain of the land and if he is managed by a hand- or pasture- mating system. The buck has the greatest genetic impact on the herd and should be well taken care of at all times.

Day length has an effect on reproduction in the buck and the doe. Bucks have the highest libido (sex drive), fertility, and semen quality and volume in late summer and fall, the 
same time that of the doe (Senger 1984; Wildeus, date unknown). As the photoperiod, or day length, gets longer, less sperm is made and more abnormal sperm cells are found in the semen. During the fall, the endocrine system also increases levels of the sex hormones, testosterone and luteinizing hormone (Ritar,1990).

\subsubsection{ANATOMY OF THE REPRODUCTIVE SYSTEM OF BUCK}

Bucks possess a structure called a filiform appendage which is an extension of the urethra beyond the end of the penis. The urethra is the duct which carries urine or sperm out of the buck's body. The penis is the organ of copulation which allows the buck to deposit semen into the vagina of the doe. It is covered by the prepuce, a fold of skin that protects the penis. The accessory sex glands, including the ampullae, seminal vesicles, prostrate and bulbourethral glands, secrete fluids into the urethi during ejaculation. These fluids contains sugar to nourish the sperm, buffers to prevent rapid changes in $\mathrm{pH}$ and other chemicals that serve to protect and propel the sperm out of the urethra and into the vagina.

The ampullae are found at the terminus of the vas deferens. The vas deferens is the duct that leads from the testis to the urethra. When the veterinarian performs vasectomy, the vas deferens are the ducts he cuts to make a "teaser buck" infertile. The vas deferens is connected to the tail of the epididymis. The epididymis is a large, winding tubule that can be felt on the side of the testis. Sperm cells that have been produced in the testis undergo a series of maturational steps as they pass from the head of the epididymis and through the body of the epididymis to the tail of the epididymis where they are stored. The testis (plural testes) is

the site where sperm are manufactured and male steroids, especially testesterone are produced. The scrotum is the pouch of skin that houses and protects the testes. The scrotum helps regulate the temperature of the testes by raising them closer to the body or lowering them away from the body. Sperm production cannot occur in the buck at or above normal internal body temperature. This is of special concern to goat producers who live in hotter climates if the external temperature rises above 103 degrees $\mathrm{F}$ for extended periods and the goats cannot cool themselves.

\subsubsection{PUBERTY}

Puberty is defined in myriad ways by researchers, but for the purposes of most producers puberty can be thought of as the time at which a goat, male or female, is capable of initiating a pregnancy. Puberty in goats can be affected by nutrition, season of birth and breed. Poor nutrition delays puberty. Kids born in the spring will be younger at puberty than kids born in the fall. In general, however, puberty in goats occurs between 4 and 6 months of age. Does should not be bred until they have reached at least 60 to 70 percent of their mature weight to avoid problems at kidding. Young bucks should be used 
sparingly since they have not finished growing. Bucks often lose weight during the breeding season, and young bucks could become infertile if they are overused.

\subsubsection{SPERMATOGENESIS}

Spermatogenesis, the origin and development of the sperm cells within the male reproductive organs, the testes. The testes are composed of numerous thin, tightly coiled tubules known as the seminiferous tubules; the sperm cells are produced within the walls of the tubules. Within the walls of the tubules, also, are many randomly scattered cells, called Sertoli cells, that function to support and nourish the immature sperm cells by giving them nutrients and blood products. As the young germ cells grow, the Sertoli cells help to transport them from the outer surface of the seminiferous tubule to the central channel of the tubule.Sperm cells are continually being produced by the testes, but not all areas of the seminiferous tubules produce sperm cells at the same time. One immature germ cell takes as long as 74 days to reach final maturation, and during this growth process there are intermittent resting phases. the testicular...

The immature cells (called spermatogonia) are all derived from cells called stem cells in the outer wall of the seminiferous tubules. The stem cells are composed almost entirely of nuclear material. (The nucleus of the cell is the portion containing the chromosomes.) The stem cells begin their process by multiplying in the process of cell duplication known as mitosis. Half of the new cells from this initial crop go on to become the future sperm cells, and the other half remain as stem cells so that there is a constant source of additional germ cells. Spermatogonia destined to develop into mature sperm cells are known as primary sperm cells. These move from the outer portion of the seminiferous tubule to a more central location and attach themselves around the Sertoli cells. The primary sperm cells then develop somewhat by increasing the amount of cytoplasm (substances outside of the nucleus) and structures called organelles within the cytoplasm. After a resting phase the primary cells divide into a form called a secondary sperm cell. During this cell division there is a splitting of the nuclear material. In the nucleus of the primary sperm cells there are 46 chromosomes; in each of the secondary sperm cells there are only 23 chromosomes, as there are in the egg. When the egg and sperm combine and their chromosomes unite, the characteristics of both individuals blend and the new organism starts to grow.

The secondary sperm cell still must mature before it can fertilize an egg; maturation entails certain changes in the shape and form of the sperm cell. The nuclear material becomes more condensed and oval in shape; this area develops as the head of the sperm. The head is covered partially by a cap, called the acrosome, which is important in helping the sperm to gain entry into the egg. Attached to the opposite end of the head is the tailpiece. The tail is derived from the secondary sperm cell's cytoplasm. In the mature sperm, it consists of a long, slender bundle of filaments that propel the sperm by their 
undulating movement. Once the sperm has matured, it is transported through the long seminiferous tubules and stored in the epididymis of the testes until it is ready to leave the male body.

\subsection{SPERM PARAMETERS}

\subsubsection{Motility}

The World Health Organization has a value of $50 \%$ and this must be measured within 60 minutes of collection. WHO also has a parameter of vitality, with a lower reference limit of $60 \%$ live spermatozoa (Cooper et al., 2010). A man can have a total number of sperm far over the limit of 20 million sperm cells per milliliter, but still have bad quality because too few of them are motile. However, if the sperm count is very high, then a low motility (for example, less than 60\%) might not matter, because the fraction might still be more than 8 million per millilitre. The other way around, a man can have a sperm count far less than 20 million sperm cells per millilitre and still have good motility, if more than $60 \%$ of those observed sperm cells show good forward movement - which is beneficial because nature favours quality over quantity.

A more specified measure is motility grade, where the motility of sperm are divided into four different grades:

Grade a: Sperm with progressive motility. These are the strongest and swim fast in a straight line. Sometimes it is also denoted motility IV.

Grade b: (non-linear motility): These also move forward but tend to travel in a curved or crooked motion. Sometimes also denoted motility III.

Grade c: These have non-progressive motility because they do not move forward despite the fact that they move their tails. Sometimes also denoted motility II.

Grade d: These are immotile and fail to move at all. Sometimes also denoted motility I.

\subsubsection{Morphology}

Regarding sperm morphology, the WHO criteria as described in 2010 state that a sample is normal (samples from men whose partners had a pregnancy in the last 12 months) if $4 \%$ (or 5th centile) or more of the observed sperm have normal morphology (Ruthmann et al.,2013).

Morphology is a predictor of success in fertilizing oocytes during in vitro fertilization to $10 \%$ of all spermatozoa have observable defects and as such are disadvantaged in terms of fertilising an oocyte. Also,sperm cells with tail-tip swelling patterns generally have lower frequency of aneuploidy(Pang et al., 2009). 
A motile sperm organelle morphology examination (MSOME) is a particular morphologic investigation wherein an inverted light microscope equipped with high-power optics and enhanced by digital imaging is used to achieve a magnification above $x 6000$, which is much higher than the magnification used habitually by embryologists in spermatozoa selection for intracytoplasmic sperm injection (x200 to $\mathrm{x} 400)$. A potential finding on MSOME is the presence of sperm vacuoles, which are associated with sperm chromatin immaturity, particularly in the case of large vacuoles.

\subsubsection{Volume}

According to one lab test manual semen volumes between $2.0 \mathrm{~mL}$ and $5 \mathrm{~mL}$ are normal (Ruthmann et al., 2013). WHO regards $1.5 \mathrm{ml}$ as the lower reference limit (RN et al., 2013). Low volume may indicate partial or complete blockage of the seminal vesicles, or that the man was born without seminal vesicles. In clinical practice, a volume of less than $2 \mathrm{~mL}$ in the setting of infertility and absent sperm should prompt an evaluation for obstructive azoospermia. A caveat to this is be sure it has been at least 48 hours since the last ejaculation to time of sample collection.

The human ejaculate is mostly composed of water. 96 to $98 \%$ of semen is water. One way of ensuring that a man produces more ejaculate is to drink more liquids. Men also produce more seminal fluid after lengthy sexual stimulation and arousal. Reducing the frequency of sex and masturbation helps increase semen volume. Sexually transmitted diseases also affect the production of semen. Men who are infected with the human immunodeficiency virus (HIV) produce lower semen volume.

\subsubsection{Color}

Semen normally has a whitish-gray color. It tends to get a yellowish tint as a man ages. Semen color is also influenced by the food we eat: foods that are high in sulfur, such as garlic, may result in a man producing yellow semen. Presence of blood in semen (hematospermia) leads to a brownish or red colored ejaculate. Hematospermia is a rare condition.

Semen that has a deep yellow color or is greenish in appearance may be due to medication. Brown semen is mainly a result of infection and inflammation of the prostate gland, urethra, epididymis and seminal vesicles. Other causes of unusual semen color include sexually transmitted infections such as gonorrhea and chlamydia, genital surgery and injury to the male sex organs.

\subsection{EPIDIDYMAL SPERMATOZOA}

When the spermatozoon leaves the testicle to the epididymis, it is a non-functional and infertile gamete. Only after the passage through the epididymis, it becomes mature and acquires progressive motility to become able to fertilize the oocyte. This maturation is 
complex and involves several factors, including the interaction of sperm with proteins that are synthesizedin each epithelium region of the epididymis. Sperm passively migrates through the epididymisand after contact with the epididymal secretions get low-molecular weight and water-soluble compounds by an isovolumetric regulatory process. These compounds can be spent together with the cell water when the cells come into contact with hypo-osmotic fluids from accessory glands or genital female tract. The volume adjustment process serves to maintain the volume pattern into the sperm cell and to prevent angulation of the flagellum, which prevents thesperm to migrate efficiently in the female reproductive tract, being unable to fertilize oocytes. The channels responsible for this regulation are located in cytoplasmic droplets. The spermatozoa located in the cranial portion of the epididymis (caput) are considered immature to present an osmolyte content reduced insufficient for complete regulation of cell volume when exposed to hypotonic solutions [Cooper TG.2007]. The movement of the sperm through the epididymis is performed mainly by the contraction of smooth muscles of the wall of the Caput and corpus region. On the cauda, the smooth muscles of the epididymal duct is generally at rest until it is stimulated to contract at the time of ejaculation for the release of sperm, thus it is responsible for the protection and storage of sperm until ejaculation.There are two moments prior to recovery of sperm that interferes directly in the success of the process. The first is the time from the death of the animal until the necropsy, anyd the second is the period of recovery of the gonads to obtain the gametes in the laboratory [Martins et al.,2007]. The higher the time of the gametes permanence in the cauda epididymis after death or after orchiectomy, the greater the damage to the sperm cell. At room temperature, motility is the first parameter affected. With the increase in the hours before recovery, there is a reduction in the percentage of moving spermatozoa, worsening from 24 hours. There are two moments for the recovery of spermatozoa from the epididymis:

a. After death

b. After orchiectomy

The most common form of spermatozoa recovery from the epididymis is after death. It is indicated in cases of use of last spermatic reserve after breeder death. It is usually recommended when the breeder is found after dead in the field in cases of sudden death from a serious illness, accidents, poisoning and stress problems. It is worth mentioning that infectious diseases can contaminate tissues with pathogenic microorganisms, and in such cases the technique is not recommended to avoid contamination. Moreover, in some infectious diseases,there is an acceleration of tissue degradation, affecting the preservation of tissues and reducing the time for manipulation. One example is infection by Clostridium chauvoei, a bacterium when multiplied produces a toxin that causes injury to the host body as well as muscles and other tissues. The acute disease is considered highly lethal.After death there is limited time to work before the occurrence of the degeneration 
of tissues (postmortem autolysis), damaging the quality of sperm. This time must be sufficient forcatching the gonads in the field and transport to the laboratory. Trained technicians are required to perform rapidly obtaining of the spermatozoa, and then adding the medium toprovide substrates necessary for maintenance of gametes.

The recovery after orchiectomy is usually performed in experimental works. Once is not common execute euthanasia in animals for research, the orchiectomy is an option to simulate the death for testis and epididymis. The interruption of blood supply to the testis and epididymis causes the same degenerative changes which occur after death. The orchiectomy isindicated in any situation where you do not want to eliminate the animal. In cases of unilateraltesticular involvement, contralateral testicle can be tapped for wildlife, the difficulty of semen collection by conventional methods such as electroejaculation and artificial vagina turns recovery from epididymis interesting. Sperm can be obtained after orchiectomy, and the animal will stay alive, but will be unable to reproduce on their own. Both techniques are considered the last chance to use male gametes. The concentration of spermatozoa recovered is limited by storage capacity in the cauda epididymis of each species. The number of insemination doses is directly proportional to this concentration.

recovery, the epididymis can be handled in two ways:

a. Room temperature (about $19^{\circ} \mathrm{C}$ )

b. Chilled $\left(4-5^{\circ} \mathrm{C}\right)$

When an animal is found dead in the field, it was exposed to climatic conditions for hours. This ambient temperature accelerates tissue degeneration with loss of sperm viability in agiven time period. This condition has been represented in previous studies to be closer toreality, to verify the time available and establish a window of opportunity to work. A largevariation in ambient temperatures was reported successfully, between 18 and $24^{\circ} \mathrm{C}$.At a temperature of $18-20^{\circ} \mathrm{C}$, it is possible to recover viable gametes, With $41.25 \%$ of progressive motility by up to 30 hours after orchiectomy (Bertol et al,.2013).Thus, after the death of bulls exposed at Ambient temperature, the ideal time until sperm recovery is up to 30 hours. With the increase of the residence time of the gametes in the cauda epididymis after death or after orchiectomy, there is greater damage to the sperm cell. In general, motility is the first parameter affected.On the other hand, in most studies the epididymis are kept at a refrigeration temperature of $5^{\circ} \mathrm{C}$ before recovery, which slows down the process of cell degradation increasing the time forcollecting viable gametes. For bulls, the maintenance of refrigerated epididymis enables theachievement of viable sperm for up to 72 hours after the death . By comparing the refrigerating temperature $\left(4.9-6^{\circ} \mathrm{C}\right)$ with room temperature $\left(21.5-17.9^{\circ} \mathrm{C}\right)$ for maintenance of the epididymis before harvesting in sheep, the highest temperature affects earlier some spermatic parameters such as the 
acrosome integrity, motility, concentration and morphology ( Lone et al., 2010) . If possible, the testicles and epididymis should be transported to the laboratory chilled to increase the time for processing. 


\subsection{Materials and Methods}

\subsection{Experimental site}

The research was carried out at the laboratory of the Veterinary Teaching Hospital Annex, Federal University of Agriculture, Makurdi, Benue state. Makurdi is located in the southern guinea Savannah, and at Latitude $7^{\circ} 14^{\prime}$ North and Longitude $8^{\circ} 21^{\prime}$ East. The area has a warm temperature range of $24^{\circ} \mathrm{C}$ to $36^{\circ} \mathrm{C}$. High temperatures are experienced between late February and April in this area. The level of rainfall is between 508 and $1016 \mathrm{~mm}$.

\subsection{Sample Collection}

Testes from 15 sexually matured bucks were used for this study, they were collected from bucks slaughtered at the goat unit of three different abbatoirs in Makurdi, Benue state. The testes weight, epididymis weight,testes length, testes circumference, and epididymis length were measured. The samples were placed in a well-insulated flask maintained at a cold condition using ice blocks immediately the animals were slaughtered before transportation to the laboratory.

\subsection{Storage Procedure}

The collected samples were preserved in a refrigerator with ice and covered with wool in a well insulated flask to prevent direct contact of the ice to the the sample. The samples were divided into 3 groups according to the time processing after collection ; 0 hour, 48 hours and 72 hours, with a total of 5 samples per group.

\subsection{Experimental Procedure}

The stored testes was recovered from the refrigerator and placed in a tray,after which the scrotal sac was carefully detached from the testes, the epididymis and blood vessel were carefully trimmed as well using a scalpel blade and scissors. The detached testes and epididymis were individually weighed and recorded. Sperm cells were recovered from the cauda epididymis by the incision method, several incisions were made on the lower end of the epididymis to enable sperm cells swim out into prewarmed three milliliters of $2.9 \%$ sodium citrate buffer in a Petri dish $(95 \mathrm{~mm})$ and placed in a water bath at $37^{\circ} \mathrm{C}$ for 30 minutes.

\subsection{Determination of Spermatozoa Livability}

Livability of sperm cells was determined by placing a drop (10 $\mu \mathrm{L})$ of sperm sample on a clean, grease-free slide and mixed with a single drop of eosin-nigrosin stain. The spermatozoa were allowed to interact with the stain for at least 2 min and then a smear was prepared. The prepared smear was air-dried and examined under oil immersion objective (100x magnification). Spermatozoa that stained either partially or completely 
were considered as dead, and spermatozoa that appeared colourless were considered as alive

\subsection{Determination of Spermatozoa Progressive Motility}

Spermatozoa progressive motility of different storage groups including control ohrs group were evaluated by placing a drop $(10 \mu \mathrm{L})$ of sperm sample on a grease-free slide. A cover slip was put over the drop and examined under the high-power objective (40x magnification) of a microscope (Olympus $\left.{ }^{\circledR}\right)$, and the percentage of progressive motility was determined and recorded.
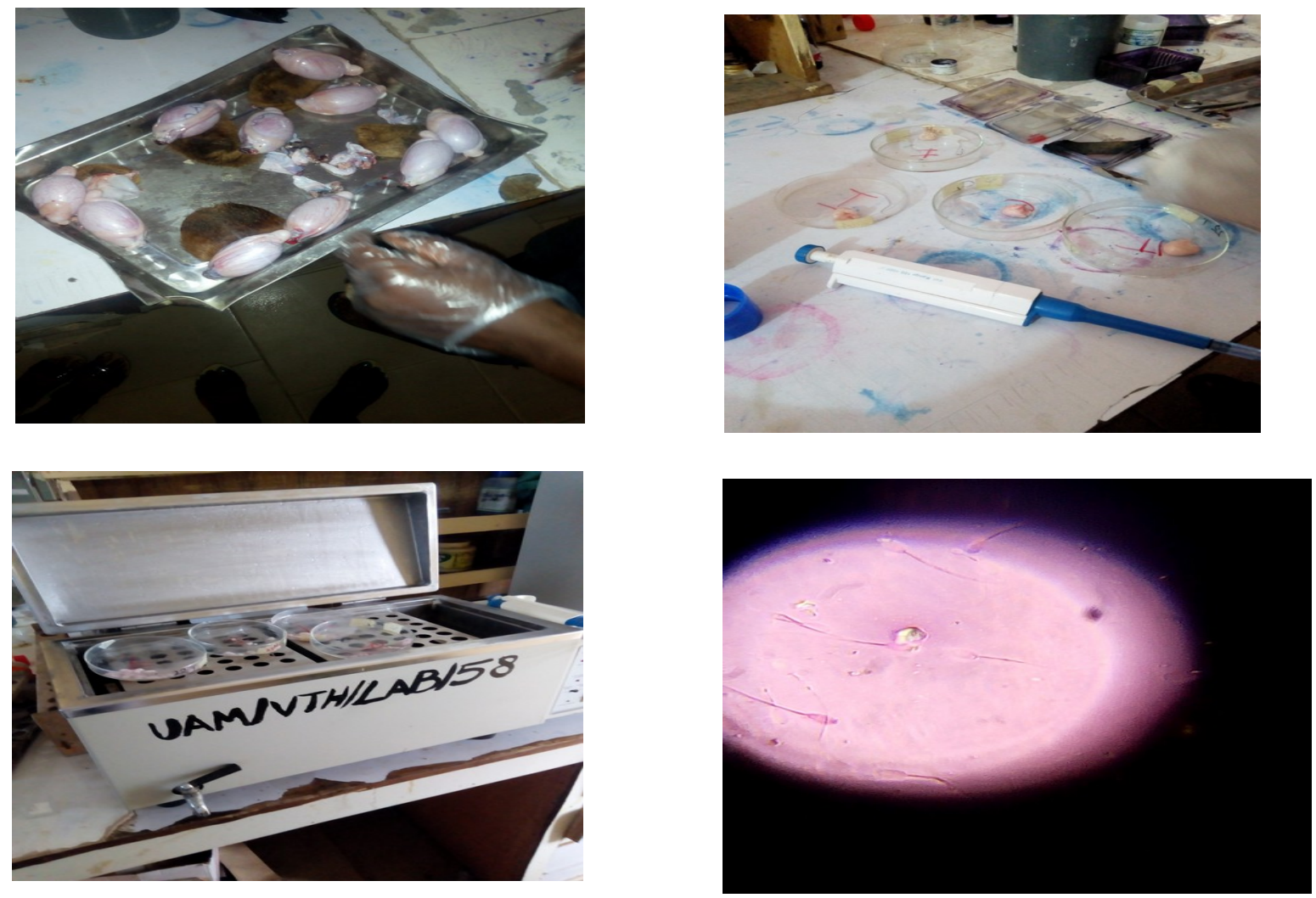


\section{References}

Cooper TG, Noonan E, von Eckardstein S, Auger J, Baker HW, Behre HM, Haugen TB, Kruger T, Wang C, Mbizvo MT, Vogelsong KM (May-Jun 2010). "World Health Organization reference values for human semen characteristics" (PDF). Human Reproduction Update. 16 (3): 231-45. doi:10.1093/humupd/dmp048. PMID 19934213.

Goat reproduction, puberty and sexual maturity, www.extension.org. Accessed December 1 3, 2011.

Rothmann SA, Bort AM, Quigley J, Pillow R (2013). "Sperm morphology classification: a rational method for schemes adopted by the world health organization". Methods in Molecular Biology. 927: 27-37. doi:10.1007/978-1-62703-038-0_4. ISBN 978-1-62703-037-3. PMID 22992901

Pang MG, You YA, Park YJ, Oh SA, Kim DS, Kim YJ (June 2009). "Numerical chromosome abnormalities are associated with sperm tail swelling patterns". Fertil. Steril. 94 (3): 1012-1020.

RN, Kathleen Deska Pagana PhD; FACS, Timothy J. Pagana MD (2013-11-22). Mosby's Manual of Diagnostic and Laboratory Tests, 5e (5 ed.). St. Louis, Missouri: Mosby.

Stonybrook, State University of New York. 1999. Archived from the original on October 17, 2007. Retrieved 2007-08-05.

Causes of Yellow Semen and Yellow Sperm: What Color is Sperm?". 12 April 2016.

Martins CF, Rumpf R, Pereira DC, Dode MN. Cryopreservation of epididymal bovine spermatozoa from dead animals and its uses in vitro embryo production. Anim ReprodSci 2007;101:326-31. doi:10.1016/j.anireprosci.2007.01.018.

Cooper TG. Sperm maturation in the epididymis: a new look at an old problem. AsianJ Androl 2007;9:533-9. doi:10.1111/j.1745-7262.2007.00285.x.

Weiss RR, Muradas PR, Graneman LC, Meira C. Freezing sperm from cauda epididymisof castrated stallions. Anim Reprod Sci 2008;107:356. doi:10.1016/j.anireprosci.2008.05.133.

Bertol MAF, Romualdo Weiss R, Tomaz-Soccol V, Ernandes Kozicki L, Silva Fujita A,Azevedo de Abreu R, et al. Viability of bull spermatozoa collected from the epididymisstored at $18-20^{\circ} \mathrm{C}$. Brazilian Arch Biol Technol 2013;56:777-83. doi:10.1590/S1516-89132013000500008

Goat reproduction, puberty and sexual maturity, www.extension.org. Accessed December 1 3, 2011 
Noble, R.C., 2004. Effect of Condition Scores on Late Pregnancy Does Subsequent Performances. Reproduction Management of Beef Cattle and Goats. Goat Workshop. Florida A\&M University.

Wilson,R.T. (1991).Small Ruminant Production and the Small Ruminant Genetic Resource in Tropical Africa. Food and Agriculture Organisation. Pp. 106-114

Ozung, P. O., Nsa, E. E.,Ebegbulem, V. N. and Ubua, J. A. (2011). The Potentials of Small Ruminant Production in Cross River Rain Forest Zone of Nigeria: A Review.Continental Journal of Animal and Veterinary Research, 3 (1): 33 - 37.

Ibrahim, A. A., Hudu, S., Tamburawa, M. S. and Ashiru, R. M.(2014). Growth Performance, Nutrient Digestibility and Haematological Parameters of Red Sokoto Goats Fed SabaraGuiera senegalensis) Leaf Meal.Iranian Journal of Applied Animal Science 4(1): 53-58.

Otoikhian, C. O S.(2012).Quantitative traits and blood biochemical characterization of White Bornu and Red Sokoto goat breeds in Nigeria.African Scientist journal,13(1): 41-48

Ebozoje, M.O. (1992). Preweaning Performance of WAD and WAD X Maradi Halfbred Goats in Ibadan, Nigeria. PhD Thesis, University of Ibadan, Ibadan, Nigeria, Pp. 239

Blench, R. (1999). Traditional livestock breeds: Geographical distribution and dynamics in relation to the ecology of West Africa. Pp. 1-62

Gall, C. (1996) Goat breeds of the world. Margraf Publishing, Weikersheim, Germany.Ibrahim, M. A. (1986). Veterinary traditional practice in Nigeria. In R. von Kaufmann, Chater, S. \& Blench, R. (Eds). Proceedings ILCA/NAPRI Symposium, Kaduna,

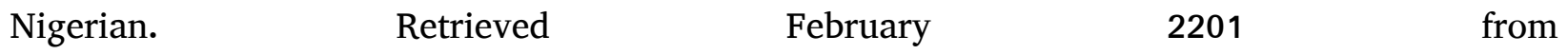
http://www.fao.org/Wairdocs/ILRI/x5463E/x5463e0b.htm\#paper9

Chiejina, S. N., Behnke, J. M. and Fakae, B. B. (2015). Haemonchotolerance in West African Dwarf goats: contribution to sustainable, anthelmintics-free helminth control in traditionally managed Nigerian dwarf goats.Parasite22:7. doi:10.1051/parasite/2015006. ISSN 1776-1042

Lone FA, Islam R, Khan MZ, Sofi KA. Effect of transportation temperature on the qualityof cauda epididymal spermatozoa of ram. Anim Reprod 2011;123:549.doi:10.1016/j.anireprosci.2010.10.012 